\title{
Meal size and intermeal interval both regulate schedule-induced water intake in rats
}

\author{
ROBERT A. ROSELLINI \\ State University of New York, Albany, New York 12222 \\ and \\ DAVID R. BURDETTE \\ University of Pennsylvania, Philadelphia, Pennsylvania 19104
}

\begin{abstract}
The present studies examined the effects of intermeal interval and pellet magnitude on the development and maintenance of schedule-induced polydipsia using a between-subjects design as contrasted with earlier investigations, which have exclusively employed within-subject procedures. In Experiment 1, pellets were delivered on one of six fixed-time schedules $(20,40,60$, 120,180 , and $240 \mathrm{sec}$ ) to different groups of rats. Although the typical bitonic function relating water intake to intermeal interval was obtained, the function showed a wide plateau ranging from 60 to $180 \mathrm{sec}$. Experiment 2 demonstrated that both intermeal interval and pellet magnitude regulate schedule-induced polydipsia. While small-magnitude pellets could support drinking only at relatively short intermeal intervals, increasing pellet magnitude to medium or large resulted in drinking at progressively longer intermeal intervals. Indeed, we observed drinking on a fixed-time 720 -sec schedule with large-magnitude pellets. These findings are derivable from the opponent-process theory of acquired motivation.
\end{abstract}

Food-deprived rats will drink substantial amounts of water when small portions of food are delivered on an intermittent schedule (e.g., Falk, 1961). This effect, schedule-induced polydipsia, has received much empirical and theoretical attention over the past decade (for reviews, see Falk, 1971, 1977; Staddon, 1977). At present, however, no single theory adequately accounts for the various aspects of the schedule-induced drinking phenomenon (Falk, 1977).

The research described here reexamined one of the more reliable determinants of the degree of schedule-induced drinking, that is, the length of time separating successive bouts of eating (i.e., the interpellet interval). Falk (1966) found that water intake of two rats exposed to an ascending series of fixedinterval (FI) values first increased to a maximum and then decreased. The highest level of scheduleinduced drinking was obtained at FI $180 \mathrm{sec}$ for one rat and at FI $90 \mathrm{sec}$ for the other rat. Subsequent investigations of the effect of interpellet interval have replicated the bitonic function obtained by Falk and, furthermore, have indicated that the relationship

This research was supported by Postdoctoral Fellowship MH00980 to the first author and Grant MH-29187 from the National Institute of Mental Health to Richard L. Solomon. The authors wish to thank Richard L. Solomon for his helpful comments on an earlier draft of this article and Robin L. Lashley for editorial assistance. Requests for reprints should be sent to Robert A. Rosellini, Department of Psychology, SUNY - Albany, Albany, New York 12222. holds (1) when food pellets are dispensed noncontingently (Bond, 1976; Hawkins, Schrot, Githens, \& Everett, 1972), (2) when meals consist of two 45-mg pellets (Flory, 1971), and (3) when the interpellet interval is progressively lengthened or shortened within each session of training (Bond, 1976). All of these experiments, and others (Keehn \& Colotla, 1971; Segal, Oden, \& Deadwyler, 1965), support the view that schedule-induced drinking generally fails to exceed baseline levels with delivery of a single 45-mg pellet when interpellet intervals are longer than approximately $4 \mathrm{~min}$ or when the intervals are longer than $480 \mathrm{sec}$ with two pellet deliveries (Flory, 1971). Even with such consistency of outcome under widely differing experimental conditions, there is no consensus regarding the particular interpellet interval that generates the highest level of water consumption. Across different studies, optimal intakes have been obtained at intervals ranging from 60 to $180 \mathrm{sec}$.

We were impressed by the fact that only withinsubject designs have been employed; that is, each subject is studied at all levels of the interpellet interval variable. This raises the question of whether the same bitonic function would obtain when subjects are exposed to a single interpellet interval and the effect of interval length is assessed between groups. In Experiment 1, separate groups of rats received $45-\mathrm{mg}$ food pellets independently of their behavior at one of six interpellet intervals that ranged from 20 to $240 \mathrm{sec}$, with the total number of pellets delivered 
in each session held constant. Thus, the present procedure provides an analysis of the effects of different interpellet intervals on induced drinking uncontaminated by prior experience with other intervals.

\section{EXPERIMENT 1}

\section{Method}

Subjects. Thirty-seven male albino rats, 100 days of age and obtained from the Holtzman Company, were used. All animals were gradually reduced to $80 \%$ of their free-feeding body weights over a 7-day period prior to the beginning of the experiment. Their ad-lib weights ranged from 351 to $412 \mathrm{~g}$. All animals were run during the light phase of a 12-h light/12-h dark cycle. They were housed in individual cages, and water was continuously available.

Apparatus. Three operant chambers were used. Each chamber was $30.5 \mathrm{~cm}$ long $\times 27.9 \mathrm{~cm}$ high $\times 25.5 \mathrm{~cm}$ wide. The two side walls were clear Plexiglas, and the front and back walls were brushed (nonreflective) aluminum. The floor consisted of $.32-\mathrm{cm}$ diam stainless steel rods spaced $1.3 \mathrm{~cm}$ apart. An inoperative lever $(5.0 \times 1.3 \mathrm{~cm})$ was centered on the front wall, $10.0 \mathrm{~cm}$ above the grid floor, and protruded $1.9 \mathrm{~cm}$ into the chamber. A food cup $(5.0 \times 3.8 \times 2.5 \mathrm{~cm})$ was located directly below the lever and rested on the floor. A $2.0-\mathrm{cm}$-diam hole located $3.8 \mathrm{~cm}$ to the right of the food cup permitted access to a drinking spout attached to a graduated $100-\mathrm{ml}$ cylinder positioned outside the chamber. A stainless steel drinking spout (2.5-mm orifice), electrically insulated from the rest of the chamber, was centered $2.0 \mathrm{~mm}$ behind the access hole. For purposes of recording licks, the water in the cylinder and the grid floor served as the two electrodes for a drinkometer circuit. Each chamber was housed in a sound-attenuating shell that was equipped with a houselight and a ventilating fan. All programming equipment was located in an adjoining room.

Procedure. On Day 1, baseline water intake was determined. The appropriate number of pellets (either 30 or 60 ) were massed in the food cup at the start of the session, and each animal was allowed to remain in the chamber for a period of time equivalent to that of each experimental session. Daily training sessions consisted of presenting 45-mg Noyes Formula $A$ food pellets independently of the rat's behavior according to one of six fixed-time (FT) schedules. The experiment was carried out in two replications, which differed in the schedule used and number of pellets delivered per session. In Replication 1, pellets were delivered to the different groups on an FT $20-\sec (\mathrm{N}=3)$, FT $40-\sec (\mathrm{N}=3)$, FT $60-\mathrm{sec}$ $(\mathrm{N}=2)$, FT $120-\sec (\mathrm{N}=2)$, or FT $180-\sec (N=2)$ schedule. A session consisted of 60 pellet deliveries. In Replication 2, pellets were delivered on an FT $60-\mathrm{sec}(\mathrm{N}=6)$, FT 120-sec $(N=7)$, FT $180-\sec (\mathrm{N}=8)$, or FT $240-\sec (\mathbf{N}=4)$ schedule. Thirty pellets were delivered during each session of the second replication. The experiment was terminated when session water intakes showed little day-to-day variability for at least five consecutive sessions. Replication 1 consisted of 16 sessions and Replication 2 of 24 sessions. Water intake was recorded for each animal for each session. In addition, water-spout contacts (licks) were recorded for three rats in each of the FT 60 and FT 120 conditions and for four rats in each of the FT 180 and FT 240 conditions of Replication 2.

\section{Results}

Since the two replications differed in the number of pellets delivered during each session, the session water intake data were converted to ratio scores (ml/ pellet) for all subjects. Data from the two replications were combined for the 60-, 120-, and 180-sec intervals.
Water intake increased steadily over sessions, with asymptotic rates maintained over the last five sessions. Figure 1 shows the mean $\mathrm{ml} /$ pellet intake averaged across the last five sessions for each of the six interpellet intervals investigated. The expected bitonic function was obtained. Lengthening the interpellet interval from 20 to $60 \mathrm{sec}$ resulted in progressively higher intake scores, which then leveled off at the $120-$ and $180-\mathrm{sec}$ intervals. However, water intake was again reduced at the $240-\mathrm{sec}$ interval. An unequal $\mathrm{N}$ analysis of variance showed that intakes of the groups differed significantly $[F(5,31)=3.71, p<$ $.001]$. Newman-Keuls post hoc tests indicated that two subsets of groups could be distinguished $(p<.05)$. One subgroup involved animals that received the FT $60-, 120-$, or 180-sec schedule, and the other subgroup consisted of animals from the FT 20 - and 240-sec conditions. The animals exposed to the FT 40-sec schedule did not differ from either of these two subsets of groups.

All animals exhibited the greatest amount of licking shortly following pellet delivery, with a subsequent decline over the second half of the interval and nearcomplete cessation of licking shortly before delivery of the next pellet. However, as presented in Figure 2, the animals in the different groups revealed different patterns of licking during their respective interpellet intervals. Animals in the FT 60 group showed the highest rate of licking during the first 10 -sec period following pellet delivery, a slightly reduced rate during the next 10-sec period, and a sharp decrease over the next three 10 -sec periods. Animals in the FT 120 and the 180 groups showed an increase in licking rate during the first two 10 -sec periods, with a gradual

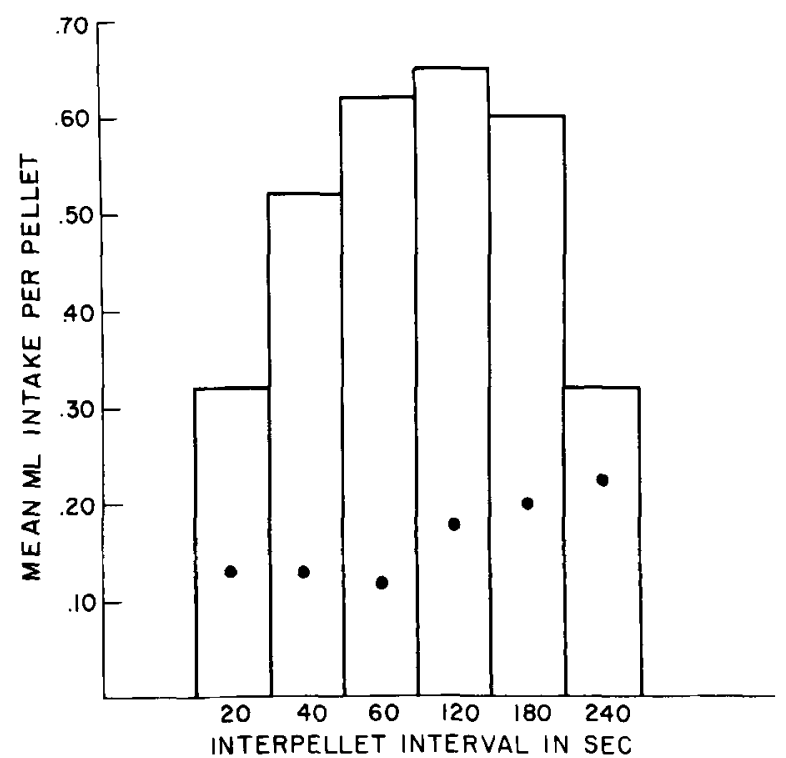

Figure 1. Mean milliliter water intake per pellet as a function of interpellet interval length in seconds. Control intake levels are indicated by the filled circle. 


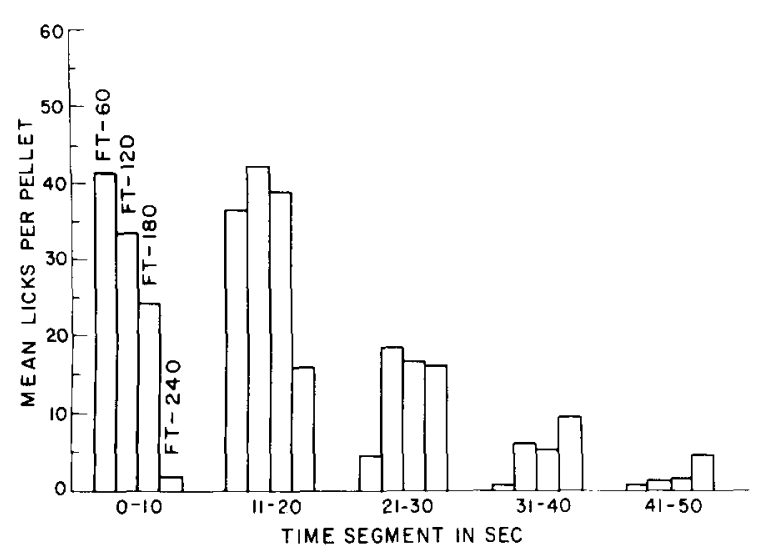

Figure 2. Mean licks per pellet in 10-sec time bins for the 60-, 120-, 180-, and 240 -sec interpellet intervals during the first $50 \mathrm{sec}$ following pellet delivery.

decrease over the following three periods. The animals in Group FT 240 showed a low rate of licking during the first 10 -sec period and an increase over the next three periods, followed by a subsequent decrease.

A Groups (4) by 10 -sec Time Periods (6) analysis of variance of the licks per pellet yielded a significant Groups main effect $[F(3,10)=6.80, p<.01]$ and a Group by Time Period interaction $[F(15,50)=$ $10.23, \mathrm{p}<.01]$. The interaction indicates that the groups had different patterns of licking during the interpellet intervals. Separate Newman-Keuls post hoc tests conducted for each of the six time periods disclosed that the groups differed in the first three periods. In the first time period, the FT 240 group licked less than any of the other groups (ps $<.05$ ). Licking in the FT 180 group occurred less reliably than in the FT 120 group or FT 60 group (ps $<.05$ ), while these latter two groups were only marginally different from each other $(.05<\mathrm{p}<.10)$. During the second time period, the FT 240 group was again lower than any of the other groups (ps $<.05$ ) and none of the remaining groups differed from each other. During the third time period, the FT 60 group was lower than any of the other groups. No significant groups differences were found during the fourth and fifth time periods.

\section{Discussion}

The bitonic function relating interpellet interval length and schedule-induced drinking obtained in this between-subjects procedure is similar to that found in within-subject investigations (cf. Bond, 1976; Falk, 1969). However, unlike these latter observations, the water intake-interpellet interval function does not gradually increase up to a maximum at the optimal interval value, followed by a subsequent progressive decline at longer interval values. Rather, when each animal is exposed to only a single interval value, the optimal interval spans a fairly wide plateau, from
60 to $180 \mathrm{sec}$ under the conditions of the present experiment. This finding may aid in reconciling the discrepancy in the reported peak intake at interpellet intervals ranging from $60 \mathrm{sec}$ (Keehn \& Colotla, 1971) to $180 \mathrm{sec}$ (Falk, 1966).

Furthermore, these results indicate that the bitonic relationship is a rather general feature of the scheduleinduced drinking paradigm. The temporal distribution of the licking between pellets is consistent with previous results (Falk, 1969) demonstrating that induced drinking is primarily a postpellet phenomenon. However, the pattern of licking was a function of interval length. Periods of peak licking tended to shift to time intervals more remote from pellet delivery as interval values were lengthened. Occurrence of drinking was directly related to the length of the interval, so that the longer the interval, the later the peak drinking occurred following pellet delivery. This shift was observed even in groups that ingested equal amounts of water per pellet (i.e., FT 60, 120, and 180). Thus, although interval values between 60 and $180 \mathrm{sec}$ produced comparable amounts of water consumption, the pattern was affected by interval length. This tendency for licking to become more flatly distributed during the early portion of the interpellet interval with increasing interval length is similar to results reported by LaBarbera and Church (1974) and Church and Deluty (1977). They found that the distribution of operant responses within a fixed interval is related to the length of the interval.

Although the relationship of schedule-induced drinking and interpellet interval seems firmly established, both from within-subject and the present between-subjects research, other considerations led us to question the validity of the general conclusion that excessive drinking always fails to develop at long interpellet interval lengths. For example, Schuster and Woods (1966) obtained considerable drinking in a rhesus monkey when multiple schedule meals were separated by as much as 1 to $6 \mathrm{~h}$. More recently, Burdette (Note 1), using a procedure in which rats were fed in one environment and were allowed to drink in a separate situation, found schedule-induced drinking when $1.0-\mathrm{g}$ meals were delivered at $25-\mathrm{min}$ intervals. Due to species and methodological differences that distinguish these two studies from those that failed to observe excessive drinking at these intervals, it is problematic to determine with confidence the reason(s) why Schuster and Woods, and Burdette, were able to demonstrate high levels of drinking.

However, these findings, in conjunction with those of Flory (1971), suggest that meal size may be an important determinant of the interpellet interval values that are capable of promoting excessive induced drinking. Flory (1971) found that two 45-mg pellet meals were capable of supporting schedule-induced drinking when meals were separated by $8 \mathrm{~min}$. 


\section{EXPERIMENT 2}

In this study, we investigated the relationship between interpellet interval length and pellet magnitude (meal size) in the schedule-induced situation using a between-subject design. Separate groups of rats received one of three different magnitude pellets $(45,190$, or $500 \mathrm{mg}$ ) dispensed according to one of three fixed-time (FT) schedules $(240,480$, or $720 \mathrm{sec})$. When session water intakes stabilized, the groups receiving either the large $(500 \mathrm{mg})$ or small $(45 \mathrm{mg})$ pellet were shifted to the medium-size pellet $(190 \mathrm{mg})$.

\section{Method}

Subjects. Fifty-four male albino rats, 100 days of age and obtained from the Charles River Company, were used. Housing and deprivation conditions were identical to those used in the previous experiment. The animals free-feeding body weights averaged $389 \mathrm{~g}$.

Apparatus. Twelve identical chambers, $24 \times 16 \mathrm{~cm}$, were used. The sides of each chamber were plywood, painted black, and the ends were opaque acrylic with a wire-mesh floor. A 50-ml graduated water tube, equipped with a rubber stopper and a stainless steel drinking spout, was attached to the exterior of each chamber. The tip of the spout was inserted into the chamber through a $2.2 \mathrm{~cm}$ aperture and protruded $2.5 \mathrm{~cm}$ into the chamber. A metal food cup $(2.5 \times 2.5 \mathrm{~cm})$ was located $6 \mathrm{~cm}$ to the left of the drinking spout. Pellets were delivered to the rat via a $1.2-\mathrm{cm}$ hole located directly above the food cup. The chambers were placed in a Wahmann Company animal rack. Chamber illumination was provided by overhead room lights. White masking noise of approximately $78 \mathrm{~dB}$ was always present during experimental sessions.

Procedure. The animals were assigned randomly to one of the nine experimental groups. The experiment was run in two replications, with two animals in each group in the first replication and four animals in each group in the second replication.

Training conditions consisted of a 3 by 3 factorial design, with each group $(\mathrm{N}=6)$ exposed to pellets of one of three magnitudes, that is, $45 \mathrm{mg}$ (small), $190 \mathrm{mg}$ (medium), or $500 \mathrm{mg}$ (large), that were delivered on one of three FT schedules (i.e., 240, 480, or $720 \mathrm{sec}$ ). Each of the 14 sessions of the study consisted of 10 pellet deliveries of the appropriate magnitude and FT schedule. Total water intake for each rat was recorded at the end of each session.

\section{Results and Discussion}

The animals that received the large-magnitude pellet at any of the three interpellet interval values and those that received the medium or small pellet at the 240 -sec interval all showed a gradual increase in water intake over the first 10 sessions of the experiment and attained asymptotic intake on the last four sessions of the study. In addition, collapsing across intervals, there was a direct relationship between pellet size and the development of drinking. These differences in rate of acquisition of drinking were confirmed by a repeated-measures analysis of variance applied to the session intake scores. The main effect of pellet magnitude $[F(2,45)=$ 24.93, $\mathrm{p}<.001]$ and the Magnitude by Session interaction $[\mathrm{F}(26,585)=2.59, \mathrm{p}<.001]$ were significant. A similar ANOVA computed over the last four sessions indicated that the effects of magnitude were apparent at asymptote as well $[\mathrm{F}(2,45)=15.05, \mathrm{p}<.001]$. A separate Interpellet Interval (3) by Session (4)
ANOVA was conducted for each magnitude group. Animals receiving the large pellet consumed approximately the same amount of water at each of the three interval values $(F<1.0)$. However, as depicted in Figure 3, water intake in the medium- and smallmagnitude groups decreased progressively as the interpellet interval was lengthened. This pattern resulted in a significant interpellet interval effect for both the medium $[\mathrm{F}(2,15)=5.51, \mathrm{p}<.05]$ and the smallmagnitude groups $[F(2,15)=(7.39, p<.05]$. Newman-Keuls post hoc tests revealed that in both magnitude groups, the $240-\mathrm{sec}$ interval was effective in producing more drinking than either the 480 - or the 720 -sec intervals ( $p s<.05$ ), which did not differ from each other.

The results of this study are congruent with earlier findings (cf. Flory, 1971; Burdette, Note 1), which demonstrate that pellet magnitude is an important determinant of the amount of water ingested in a schedule-induced situation. In addition, our results extend the generality of this magnitude effect and show that schedule-induced polydipsia can be obtained at considerably longer interpellet intervals than had previously been reported. Falk (1969) reported that very little drinking occurred if pellets were delivered on a fixed-interval schedule of 300 or $360 \mathrm{sec}$. However, with the large-magnitude pellet, we observed considerable water intake on a FT 720 -sec schedule. The present results, then, show that schedule-induced water intake is a function of both the pellet magnitude and the interval at which the pellet is delivered.

\section{GENERAL DISCUSSION}

The present studies demonstrate that although the bitonic function relating water intake to interpellet interval length obtains not only in within-subject,

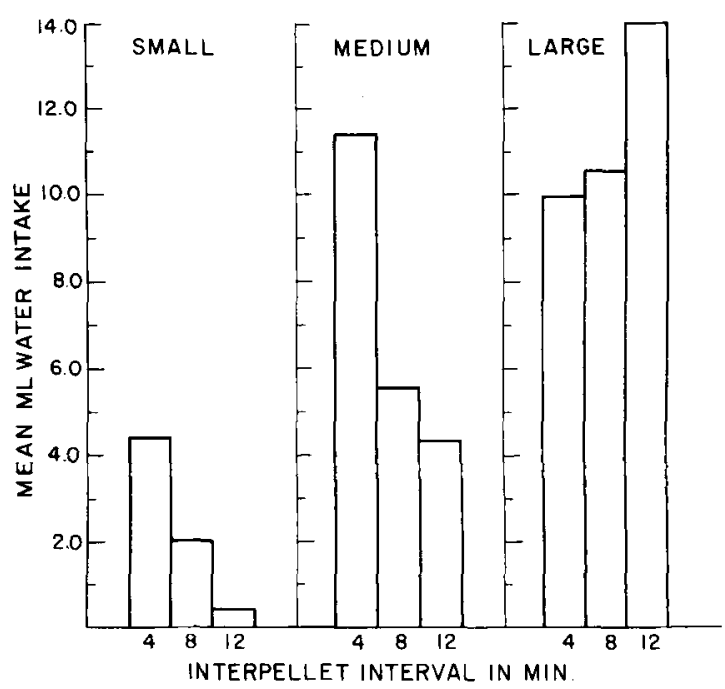

Figure 3. Mean milliliter asymptotic water intake as a function of pellet magnitude (small, medium, large) and interpellet interval $(4,8$, and $12 \mathrm{~min})$. 
but also in between-subjects, designs, the specific point at which the curve decreases is a function of both interval length and pellet magnitude. Indeed, with a 500-mg pellet, we observed approximately equal intake at all three widely different interpellet interval values.

It is difficult for most hypotheses that attempt to explain schedule-induced polydipsia to account for the interaction between interval length and pellet magnitude. For example, emotional hypotheses of schedule-induced polydipsia such as frustration (Denny \& Ratner, 1970; Thomka \& Rosellini, 1976) hold that termination of consumption of the pellet induces frustration, which in turn energizes the most probable behavior-in this case, drinking. While frustration may vary as a function of pellet magnitude (Dunlap et al., 1974; Gallup \& Altomari, 1969), it is not immediately clear why it should vary as a function of interpellet interval length. The consummatory-rate hypothesis (Falk, 1969) also seems unable to account for the present results. This hypothesis holds that water intake in the schedule-induced polydipsia situation is inversely related to rate of food consumption. However, the present results, in agreement with experiments that have held number of pellets per session constant (Bond, 1973) or that have expressed the data in terms of intake per pellet (Flory, 1971), show that as consummatory rate is increased, water intake also increases, at least within the values investigated. For example, the animals that were exposed to the mediumsize pellet decreased intake with decreasing consummatory rate (increasing interpellet interval), while the animals given the large pellet showed no modulation of intake with changes in consummatory rate.

Recently, a general theory of acquired motivation has been proposed by Solomon and Corbit (1974) that seems capable of accounting for many of the present results. Briefly, this model assumes that exposure to hedonic stimuli results in a primary affective process whose strength is a function of the intensity, quality, and duration of the inducing stimulus. This primary, or a-process, controls a slave, or opponent process, which is of opposite hedonic sign. The opponent, or b-process, is held to be sluggish in its onset and decay characteristics. The opponent is held to strengthen as a function of experience, and its magnitude is proportional to the strength of the primary a-process. This theory is primarily concerned with the aftereffects of hedonic stimuli.

Opponent-process theory can be applied to scheduleinduced polydipsia by assuming that consumption of the food pellet induces an hedonically positive primary process. The a-process triggers an opponent process that is hedonically negative and that persists after termination of the inducing stimulus. Thus, shortly following pellet consumption, the animal is in an hedonically aversive state, which is presumably reflected in water consumption.
This opponent-process view suggests that both pellet magnitude and interpellet interval manipulations should have important consequences for water intake in a schedule-induced situation. Since the strength of the a-process and, consequently, the b-process is held to be a function of the intensity of magnitude of the inducing stimulus, water intake should then increase with increasing pellet magnitude, as indeed was found to be the case in Experiment 2. In addition, the interpellet interval length should be an important determinant of water intake. The opponent is assumed to grow in strength as a function of experience. However, the growth of the opponent is also dependent on the interstimulus interval (Solomon, 1977; Starr, 1978). That is, if the interval between exposures to the a-process inducing stimulus is sufficiently long, the b-process may not grow. This notion of a critical decay duration, proposed by Starr (1978), seems capable of accounting for the bitonic nature of schedule-induced polydipsia. Thus, the theory suggests that if polydipsia is an index of an underlying opponent process, it should be modulated both by mealmagnitude and meal-interval manipulations. Meal magnitude directly affects the strength of the opponent process, with larger meals supporting a stronger opponent. This would result in stronger opponents having a longer decay time, which would allow for the strengthening of the opponent at longer intermeal intervals, thus resulting in larger intake of water at longer interpellet intervals. This view further suggests, as has been repeatedly demonstrated, that drinking in the schedule-induced situation should be largely postpellet.

It should be noted, however, that other factors beyond the scope of opponent-process theory also play a role in this phenomenon. Opponent-process theory is primarily nonassociative. However, associative effects clearly modulate at least the expression of schedule-induced polydipsia. For example, in Experiment 1 , the between-pellet pattern of licking was strongly affected by the length of the interval. Thus, it seems that the expectancy of subsequent feeding opportunities helps to determine the way licking is allocated within the interpellet interval. In agreement with such an associative effect, Millenson, Allen, and Pinker (1977) have recently reported that it is more difficult to obtain schedule-induced polydipsia when pellets are delivered on a random-interval than on a variable-interval schedule. And Lashley and Rosellini (1980) have found it more difficult to obtain drinking on a random-time than on a fixed-time schedule. These findings suggest that associative factors, possibly the conditioning of Pavlovian states, may be important for the expression of adjunctive behaviors. However, it must be emphasized that the modulation of polydipsia by associative or physiologic (i.e., satiety) factors does not obviate the importance of considering the role of nonassociative factors in adjunctive be- 
havior. Indeed, the opponent-process view suggests that manipulations that have as yet received little attention, such as pellet quality, should be important modulators of adjunctive behavior.

\section{REFERENCE NOTE}

1. Burdette, D. R. Arousal and schedule-induced drinking in rats as a function of meal size and shift in meal size. Manuscript submitted for publication, 1979.

\section{REFERENCES}

Bond, N. Schedule-induced polydipsia as a function of the consummatory rate. Psychological Record, 1973, 23, 377-382.

BonD, N. Schedule-induced polydipsia as a function of the interval between food pellets, Bulletin of the Psychonomic Society, 1976, 7, 139-141.

Church, R. M., \& Deluty, M. Z. Bisection of temporal intervals. Journal of Experimental Psychology: Animal Behavior Processes, 1977, 3, 216-228.

Denny, M. R., \& Ratnfa, S. C. Comparative psychology. Homewood, Ill: Dorsey Press, 1970.

Dunlap, W. P., Hughes, L. F., Dachowski, L., \& O'Brien, T. J. The temporal course of the frustration effect. Learning and Motivation, 1974, 5, 484-497.

FALK, J. I. The behavioral regulation of water-electrolyte balance. In $\mathrm{M}$. R. Jones (Ed.), Nebraska symposium on motivation. Lincoln: University of Nebraska Press, 1961.

FALK, J. L. Schedule-induced polydipsia as a function of fixedinterval length. Journal of the Experimental Analysis of Behavior, $1966,9,37.39$.

FALK, J. L. Conditions producing psychogenic polydipsia in animals. Annals of the New York Academy of Science, 1969, 157, 569-593.

FALK, J. L. The nature and determinants of adjunctive behavior. Physiology \& Behavior, 1971, 6, 577-588.

FALK, J. L. The origin and function of adjunctive behavior. Animal Learning \& Behavior, 1977, 5, 325-335.

Flory, R. K. The control of schedule-induced polydipsia: Frequency and magnitude of reinforcement. Learning and Motivation, 1971, 2, 215-220.

Gallup, G. G., \& Altomari, T. S. Activity as a postsituation measure of frustrative nonreward. Journal of Comparative and Physiological Psychology, 1969, 68, 382-384.

Hawkins, T. D., Schrot, J. F., \& Everett, P. B. Scheduleinduced polydipsia: An analysis of water and alcohol ingestion. In R. M. Gilbert \& J. D. Keehn (Eds.), Schedule effects: Drugs, drinking, and aggression. Toronto: University of Toronto Press, 1972.

Keenn, J. D., \& Colotla, V. A. Schedule-induced drinking as a function of interpellet interval. Psychonomic Science, 1971, $23,69-71$.

LaBarbera, J. D., \& Church, R. M. Magnitude of fear as a function of expected time to an aversive event. Animal Learning \& Behavior, 1974, 2, 199-202.

Lashley, R. L., \& Rosellini, R. A. Modulation of scheduleinduced polydipsia by Pavlovian conditioned states. Physiology \& Behavior, 1980, 24, 411-414.

Milienson, J. R., Alilen, R. B., \& Pinker, S. Adjunctive drinking during variable and random-interval food reinforcement schedules. Animal Learning \& Behavior, 1977, 5, 285-290.

Schuster, C. R., \& Woons, J. H. Schedule-induced polydipsia in the rhesus monkey. Psychological Reports, 1966, 19, 823-828.

Segal, E. F., Odfn, D. L., \& Dfanwyler, S. A. Determinants of polydipsia: IV. Free-reinforcement schedules. Psychonomic Science, 1965, 3, 11-12.

Solomon, R. L. An opponent process theory of motivation: The affective dynamics of drug addiction. In J. D. Maser \& M. E. P. Seligman (Eds.), Psychopathology: Experimental models. San Francisco: Freeman, 1977.

Solomon, R. L., \& Corbit, J. D. An opponent-process theory of motivation: I. Temporal dynamics of affect. Psychological Review, 1974, 81, 119-145.

Staddon, J. E. R. Schedule-induced behavior. In W. K. Honig \& J. E. R. Staddon (Eds.), Handbook of operant behavior. New York: Prentice-Hall, 1977.

StaRr, M. D. An opponent-process theory of motivation: VI. Time and intensity variables in the development of separationinduced distress calling in ducklings. Journal of Experimental Psychology: Animal Behavior Processes, 1978, 4, 338-355.

Tномка, M. L., \& Roselilini, R. A. Frustration and the production of schedule-induced polydipsia. Animal Learning \& Behavior, 1976, 3, 380-384.

(Received for publication March 10, 1980; revision accepted July 15, 1980.) 